\title{
Machinability Study of Al-5Cu-TiB 2 In-situ Metal Matrix Composites Fabricated by Flux-assisted Synthesis
}

\author{
A. Mahamani \\ Department of Mechanical Engineering, Swetha Institute of Technology and Science for \\ Women, \\ Tirupati-517561, India \\ Corresponding author: mahamanisudhan@gmail.com
}

\begin{abstract}
In-situ composites are multiphase materials where the reinforcing phase is synthesized by a chemical reaction. The reinforcement generated by this route is very small in size and homogeneously distributed in the matrix. Adoption of the engineering application of this material requires a systematic study of machinability characteristics. This work is an attempt to understand the machinability behavior of the Al-5Cu-TiB ${ }_{2}$ in-situ metal matrix composites fabricated by Flux-assisted Synthesis. The focus of this study is to investigate the effect of the cutting speed and feed rate on flank wear, cutting force, and surface roughness. The contribution of this paper is to study the influence of in-situ-formed $\mathrm{TiB}_{2}$ reinforcement on the machinability of Al-5Cu alloy. It was found that the increase in cutting speed increased the flank wear, reduced the cutting force, and minimized the surface roughness. Increase in the feed rate increased the flank wear, cutting force, and surface roughness. A higher reinforcement ratio increased the tool wear, reduced the cutting force, and increased the surface roughness. These findings can provide suitable machining parameters in turning of $\mathrm{Al}-5 \mathrm{Cu}-\mathrm{TiB}_{2}$ in-situ metal matrix composites.
\end{abstract}

Keywords: In-situ composite, Flank wear, cutting force, surface roughness

\section{INTRODUCTION}

Composite materials produced by the in-situ route are an innovation of the light weight material system. Flux-assisted synthesis is a more popular method to produce in-situ composites with $\mathrm{TiB}_{2}$ and $\mathrm{ZrB}_{2}$ reinforcements. In-situ composites offer better mechanical properties when compared to the composites produced by the conventional method [1]. Greater bonding strength and good thermodynamic stability of these composites makes them suitable for various engineering applications [2]. Pure, small, and fine reinforcement particles are generated by high temperature exothermic reactions, while in-situ synthesis [3]. In-situ chemical reaction boils the molten composite. Therefore, the reinforcement particles are distributed throughout the mold. 
This action facilitates the homogeneous distribution of reinforcements [4]. Typical application of in-situ composites includes the wear parts of pumps, valves, and chute liners [5]. The $\mathrm{Al}^{-\mathrm{TiB}_{2}}$ composite has better high temperature properties than conventional composites [6]. Synthesis, characterization, and mechanical properties of in-situ $\mathrm{Al}_{-} \mathrm{TiB}_{2}$ composites are widely reported in literatures [7-9]. Fan, T et al., [10] studied the effect of adding alloying elements in the Al-TiB 2 in-situ composites fabricated by flex-assisted synthesis. They concluded that the addition of the copper elements promotes the reinforcement precipitation. Lu, L et al., [11] synthesized Al-4Cu$\mathrm{TiB}_{2}$ in-situ metal matrix composite. The characterization of this composite indicates that the size of the $\mathrm{TiB}_{2}$ particles is $0.5 \mu \mathrm{m}$ to $1 \mu \mathrm{m}$ size. Liang $\mathrm{Y}$ et al., [12] conducted a thermodynamic analysis of formation of in-situ $\mathrm{TiB}_{2}$ formation as cast $\mathrm{Al}-4.5 \mathrm{Cu}$ alloy in flux-assisted synthesis process. Herbert, M.A. et al., [13] carried out a microstructure study of Al-4Cu alloy and Al$4 \mathrm{Cu}-\mathrm{TiB}_{2}$ in-situ composite. The analysis of the result indicates that the formation of coarse dendrite structures in $\mathrm{Al}-4 \mathrm{Cu}$ alloy whereas in the composite there are irregular rosette-shaped grains with TiB2 particles at the boundaries of the grains. Kumar, S. et al., [14] studied the influence of in-situ-formed TiB2 particles on the abrasive wear behavior of Al-4Cu alloy. Abrasive wear resistance of the $\mathrm{Al}-4 \mathrm{Cu}$ alloy improved with the addition of $\mathrm{TiB}_{2}$ particles. The hardness of the composite increased when the $\mathrm{TiB}_{2}$ content was raised. The component produced by composite materials requires a machining process to achieve the required dimensions. Therefore, industrial application of these composites will be impossible without addressing the machinability issues. Surface finish, tool wear, and cutting force are the important indices assessing machinability behavior. Surface integrity of the machined-component determines the ability of materials to withstand severe conditions of stress, temperature, and corrosion [15]. Tool wear plays an important role in forming the machined surface, controlling cutting, reducing the tool cost, and the machining time [16]. Cutting force carries the information about frictional characteristics in the machining interface. Machinability of the ex-situ composites are widely reported in literature. The studies on machinability behavior of in-situ composites are very limited. Ozcatalbas Y., [17] carried out an experimental investigation on machinability behavior of $\mathrm{Al}-\mathrm{Al}_{4} \mathrm{C}_{3}$ in-situ composites. The micro-crack propagation at the particle-matrix interface facilitates the fracturing through the chip cross-section whose effects reduce the cutting force. The homogeneous microstructure and high hardness of the composite reduce the build-up edge formation that improves the surface roughness. Ozcatalbas Y., [18] investigated the chip and build-up edge formation in machining of the in-situ $\mathrm{Al}-\mathrm{Al}_{4} \mathrm{C}_{3}$ composites. The morphologies of chip routes were determined by using the quick stop device. It was observed that the small size of the particle and high hardness of the composite caused discontinuous chip formation and increased the chip cutting ratio. Rai R.N., et al., [19] conducted the experiments on the machining of Al-TiC in-situ composite. They reported the chip formation and cutting force measurements during the shaping operation. High volume fraction of the TiC particles caused discontinuous and favorable chip formation without any build-up edge formation. The cutting force was minimized due to the propagation of micro cracks at the particle-matrix interface. Size and morphology of the $\mathrm{TiC}$ particles present in the composite were found to have influenced surface roughness. Anandakrishnan V., Mahamani A., [20] investigated machinability of the insitu Al6061- $\mathrm{TiB}_{2}$ composites. They reported the effects of speed, feed, and depth of cut on flank wear, cutting force, and surface roughness. It was observed that the presence of small and fine $\mathrm{TiB}_{2}$ particles exercised significant influence on machinability. The literature survey indicates that the machinability study of $\mathrm{Al}-4 \mathrm{Cu}-\mathrm{TiB}_{2}$ has not been addressed. In this direction, an attempt has been made to study the effects of cutting speed and feed rate on flank wear, cutting force, 
and surface roughness in turning these composites with the different reinforcement ratio. The contribution of this paper is to study the influence of in-situ formed $\mathrm{TiB}_{2}$ reinforcement on the machinability of Al-5Cu alloy.

\section{PRODUCTION AND CHARACTERIZATION OF THE COMPOSITES}

$\mathrm{Al}-4.5 \mathrm{Cu} / \mathrm{TiB}_{2}$ in-situ composites are produced from $\mathrm{K}_{2} \mathrm{TiF}_{6}, \mathrm{KBF}_{4}, \mathrm{Cu}-\mathrm{Al}$ salt system by mixed salt reaction. Measured quantities of these preheated halides salts added in the aluminum melt at $850^{\circ} \mathrm{C}$. These halide salts induce an exothermic chemical reaction and increase the temperature of the melt up to $1300^{\circ} \mathrm{C}$. There is a two-stage chemical reaction that occurs at this temperature. In the first stage, $\mathrm{Al}_{3} \mathrm{Ti}$ and $\mathrm{AlB}_{2}$ phases are formed, then, these phases are decomposed as $\mathrm{TiB}_{2}$ and Cryolite slag. The equation for the reaction is shown below. Cryolite slag ( $\mathrm{KAlF}_{4}$ and $\mathrm{K}_{3} \mathrm{AlF}_{6}$ phases) floating on the molten melt is removed. Now the molten melt contains Al-Cu-Ti-B- system. The molten melt is poured in to the $55 \varnothing \mathrm{X} 350 \mathrm{~mm}$ cast iron mold. Composites are fabricated with the reinforcement ratio of $0 \%, 3 \%$, and $6 \% \mathrm{TiB}_{2}$ particles in the Al-5Cu alloy.

\section{$3 \mathrm{~K}_{2} \mathrm{TiF}_{6}+13 \mathrm{Al} \rightarrow 3 \mathrm{TiAl}_{3}+3 \mathrm{KAlF}_{4}+\mathrm{K}_{3} \mathrm{AlF}_{6}$ $2 \mathrm{KBF}_{4}+3 \mathrm{Al} \rightarrow \mathrm{AlB}_{2}+2 \mathrm{KAlF}_{4}$}

The fabricated composites are characterized by EDAX, SEM, and micro-hardness analysis. The EDAX pattern for the $\mathrm{Al}-4 \mathrm{Cu}-6 \% \mathrm{TiB}_{2}$ in-situ composite was recorded (Hitachi S-300H model) and displayed in Figure 1. Lithium drift silicon detector analyzer with the operating voltage of 20KV and 500x magnification was used to record the spectrum. Figure 1 confirms the presence of $\mathrm{Cu}$ and $\mathrm{TiB}_{2}$ reinforcements. Presence of potassium and fluoride elements due to the slag entrapments in the aluminum matrix are not detected in the spectrum, which reveals the chemical stability of the composite. The micro-structure analyses of the composite samples are carried out by using scanning electron microscopy (JEOL $6360 \mathrm{LV}$ model). Figure 2 shows the micrographic view of $\mathrm{Al}-4 \mathrm{Cu}$ alloy. The $\mathrm{CuAl}_{2}$ formation is found in the grain boundaries of the matrix. $\mathrm{Al}_{2} \mathrm{Cu}$ is uniformly distributed in the matrix. Boiling the molten composite at high temperatures will distribute the reinforcement particles and $\mathrm{Al}_{2} \mathrm{Cu}$ uniformly. This action will minimize the heterogeneity in microstructure of the composite. There are very fine $\mathrm{Al}_{2} \mathrm{Cu}$ phase precipitated from the matrix. $\mathrm{Al}_{2} \mathrm{Cu}$ and $\mathrm{Al}$ bond well. So the precipitation of $\mathrm{Al}_{2} \mathrm{Cu}$ strengthens $\mathrm{Al}-4.5 \mathrm{Cu}$ matrix. Figure 3 shows the scanning electron microscopy of $\mathrm{Al}-4 \mathrm{Cu}-6 \% \mathrm{TiB}_{2}$ in-situ metal matrix composite. The micron-size $\mathrm{TiB}_{2}$ particle along with $\mathrm{Al}_{2} \mathrm{Cu}$ is trapped in to the grain boundaries of the aluminum matrix. Figure 4 shows a typical microscopic view focused on the $\mathrm{Al}_{2} \mathrm{Cu}$ phase. The $\mathrm{TiB}_{2}$ particles are surrounded by the $\mathrm{Al}_{2} \mathrm{Cu}$ phase. Table 1 shows the micro-hardness of the composites is evaluated by using the Vickers's micro-hardness tester (MH06 model) at a load of 25 grams with 3 seconds dwell time. Hardness values are measured in three different places in the composite and the average value is reported in Table 1 . Table 1 shows that there is an $8 \%$ increase in hardness observed when adding 3\% TiB2 in the $\mathrm{Al}-4 \mathrm{Cu}$ alloy. It is also seen from Table 1 that a significant improvement in the hardness of $\mathrm{Al}-4 \mathrm{Cu}-6 \%$ $\mathrm{TiB}_{2}$ in-situ composite was observed when compared to the $\mathrm{Al}-4 \mathrm{Cu}$ alloy. Therefore, the increase in hardness of the composite confirms the presence of reinforcement. It is also noted that the hardness of these in-situ composites increases when increasing the reinforcement ratio. 
Table 1 Micro hardness analysis of the composites

\begin{tabular}{|c|c|c|c|c|}
\hline Composites & \multicolumn{4}{|c|}{ Micro hardness $\left(\mathrm{H}_{\mathrm{V}}\right)$} \\
\cline { 2 - 5 } & $\begin{array}{c}\text { Trail } \\
\text { I }\end{array}$ & $\begin{array}{c}\text { Trail } \\
\text { II }\end{array}$ & $\begin{array}{c}\text { Trail } \\
\text { III }\end{array}$ & Average \\
\hline Al-4Cu alloy & 116 & 122 & 126 & 121 \\
\hline $\begin{array}{c}\mathrm{Al}-4 \mathrm{Cu}-3 \% \\
\mathrm{TiB}\end{array}$ & 133 & 123 & 137 & 131 \\
\hline $\begin{array}{c}\mathrm{Al}-4 \mathrm{Cu}-6 \% \\
\mathrm{TiB}_{2}\end{array}$ & 145 & 135 & 149 & 143 \\
\hline
\end{tabular}

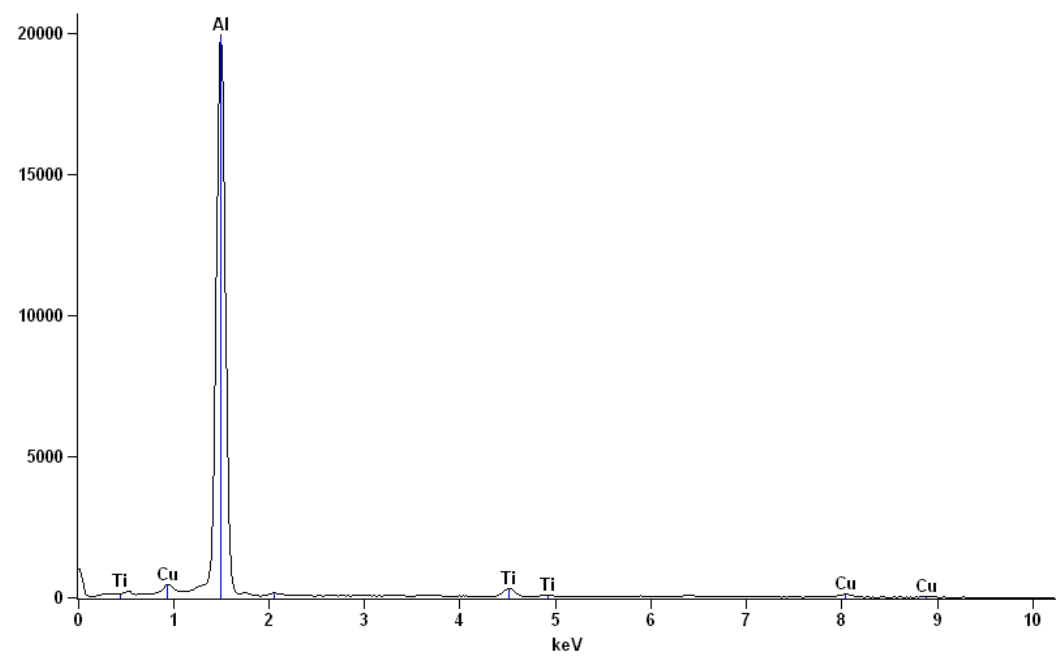

Figure 1 EDAX spectrum of $\mathrm{Al}-\mathrm{Cu}-6$ \% TiB2

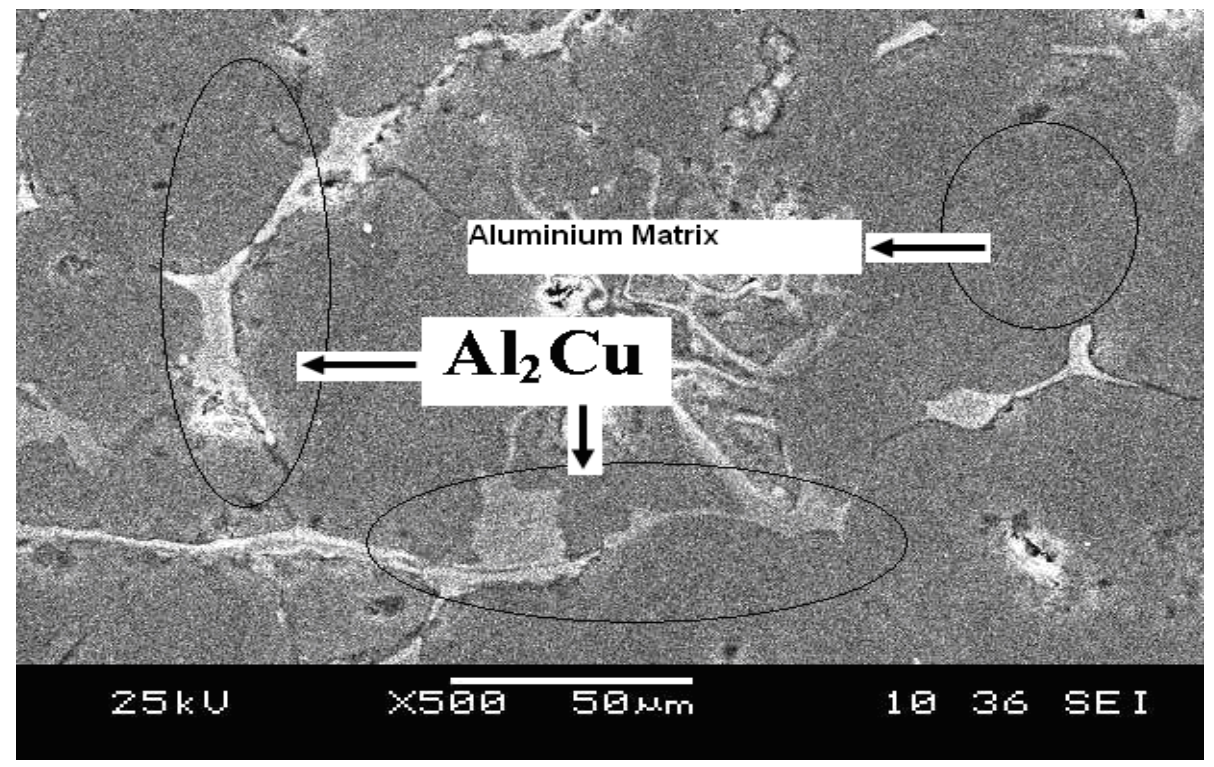


Figure 2 Microstructure of $\mathrm{Al}-\mathrm{Cu}$ alloy

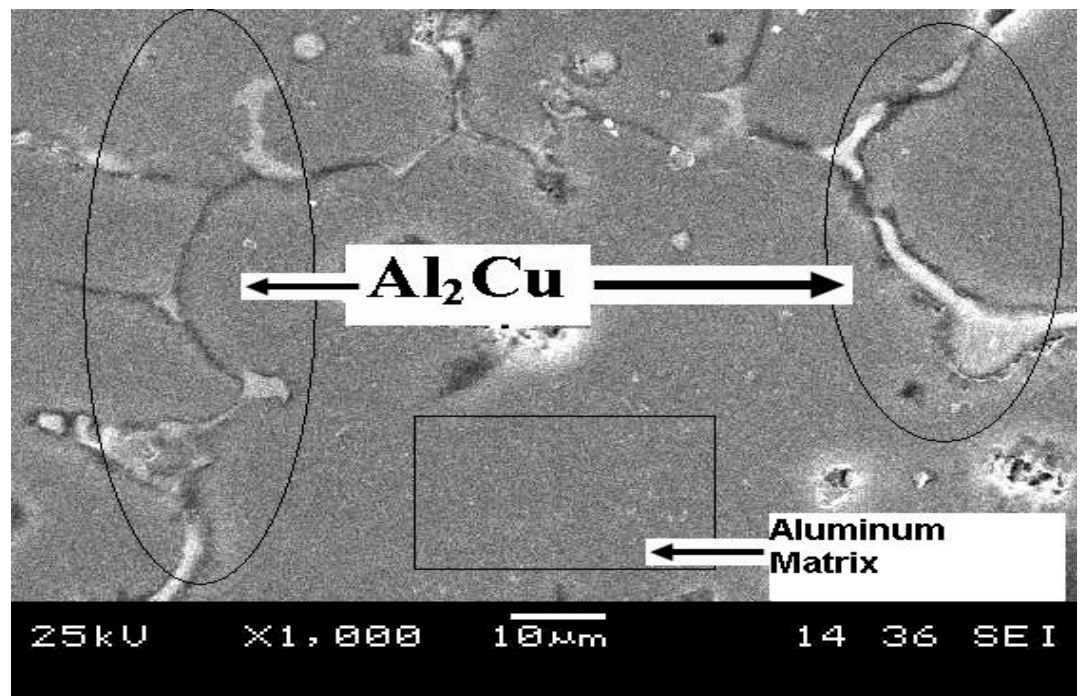

Figure 3 Microstructure of $\mathrm{Al}-\mathrm{Cu}-3 \% \mathrm{TiB}_{2}$ in-situ metal matrix composite

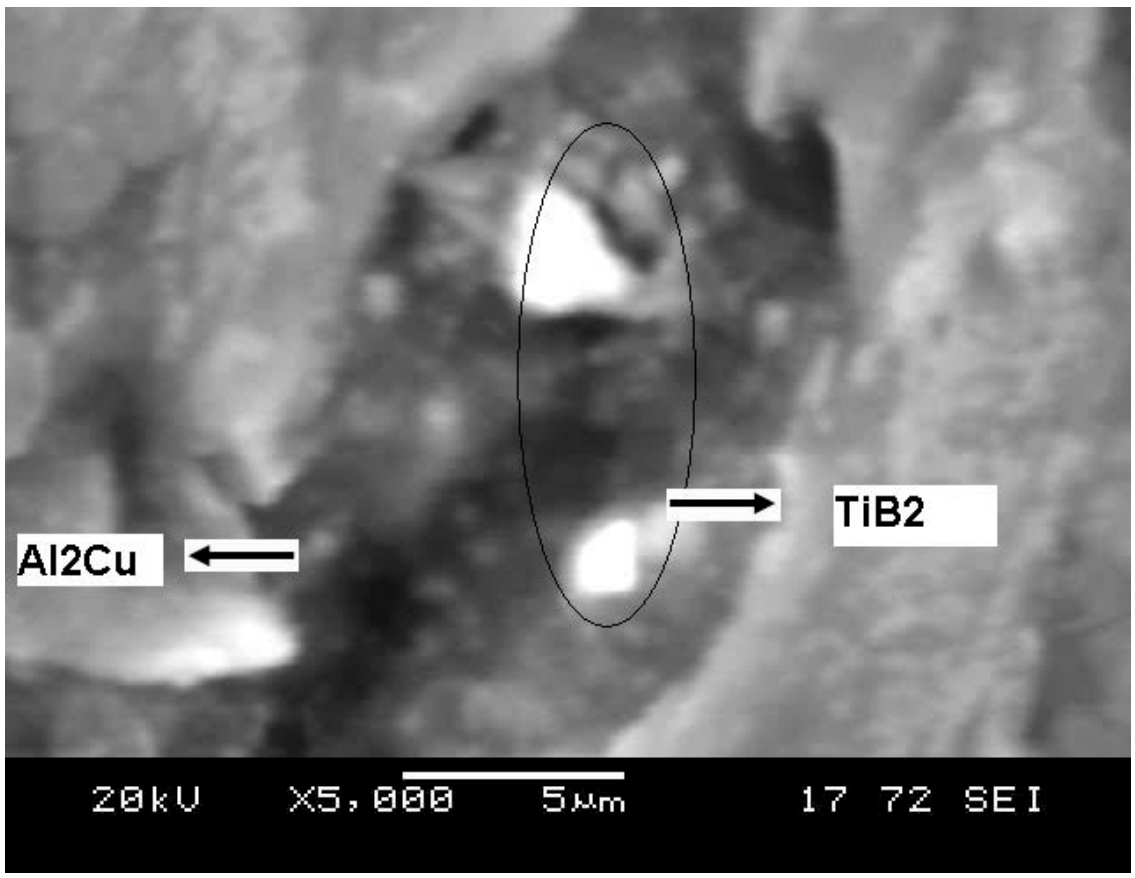

Figure 4 Microstructure of $\mathrm{Al}-\mathrm{Cu}-6 \% \mathrm{TiB}_{2}$ in-situ metal matrix composite

\section{MACHINING TEST}

A machinability study was carried out on Turn master-35 lathe supplied by Kirloskar, India. The experimental setup for machining test is shown in Figure-5. Uncoated tungsten carbide insert with the specification of SNMG120408 MTTT5100 was clamped in a rigid tool holder. The insert has clearance angle $7^{\circ}$, cutting edge angle $75^{\circ}$, and nose radius $0.8 \mathrm{~mm}$. Specification of 
the tool holder was PSBNR-2525M12. The length of turning is $110 \mathrm{~mm}$. No chip breaker was used in the experiment. The average flank wear was measured using Mitutoya microscope with $30 \times$ magnification. SJ210 stylus type roughness tester (Mitutoya make, $0.001 \mu \mathrm{m}$ ) was used for measuring surface roughness. The cut of length of roughness measurement was $25 \mathrm{~mm}$. The cutting force was measured using a Kistler Dynamometer (model 9257B). Data acquisition was carried out by appropriate software Dynaware Kistler. Machining test was conducted in dry cutting condition. During experiments, only one parameter was varied while others were held constant to observe the effects of variation of an individual input parameter on the output parameter. The selected machining parameters and their ranges are given in Table- 2 .

Table 2 Experimental conditions

\begin{tabular}{|c|c|c|}
\hline Parameters & Units & Ranges \\
\hline Cutting speed & $\mathrm{m} / \mathrm{min}$ & $50,75,100,125$ and 150 \\
\hline Feed rate & $\mathrm{mm} / \mathrm{rev}$ & $0.1,0.15,0.2,0.25$ and 0.3 \\
\hline Cutting depth & $\mathrm{mm}$ & $0.5,0.75,1,1.25$ and 1.5 \\
\hline
\end{tabular}

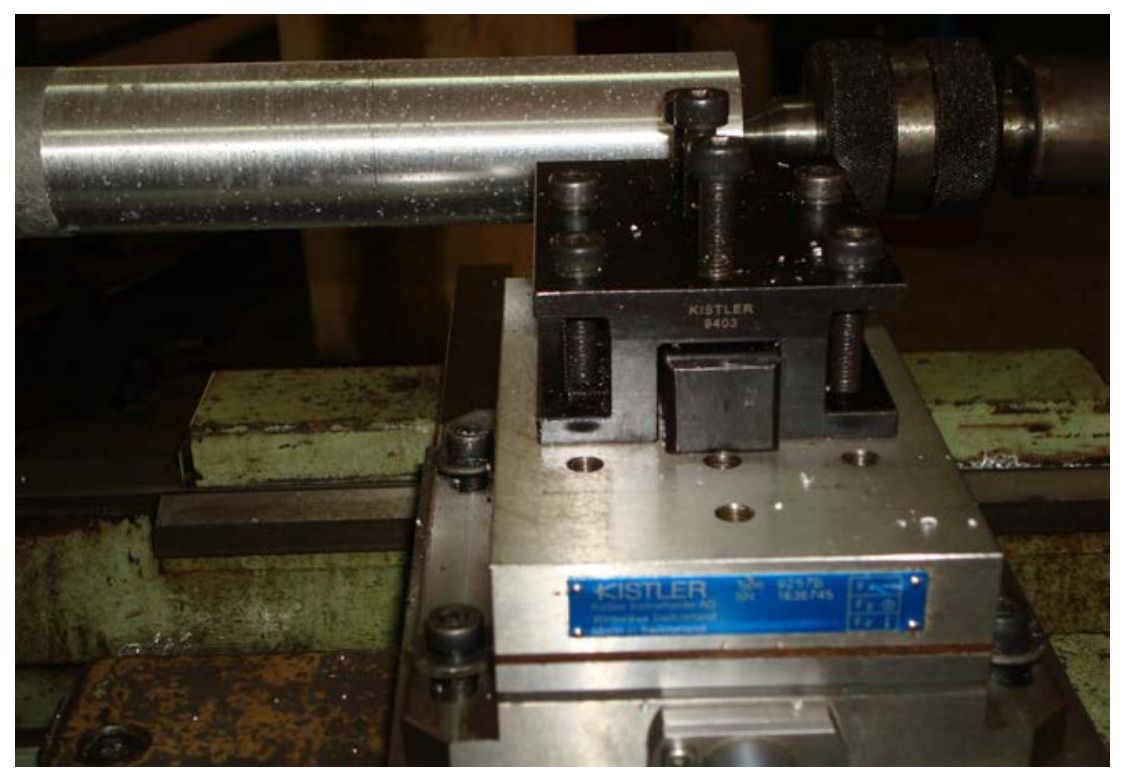

Figure 5 photographic view of experimental set up with kistler dynamometer

\section{RESULT AND DISCUSSION}

\subsection{Mechanism of In-Situ Formation}

$\mathrm{Al}-5 \mathrm{Cu}-\mathrm{TiB}_{2}$ in-situ composite was successfully produced by flux-assisted synthesis. The material characterization confirmed the presence of $\mathrm{ZrB}_{2}$ indicating the purity of materials. Formation of $\mathrm{ZrB}_{2}$ occurred at $950^{\circ} \mathrm{C}$, in the melt during the exothermic reaction. Therefore, no oxide layer formation occurred on the surfaces of $\mathrm{TiB}_{2}$. The pure and active reinforcement 
promoted the thermodynamic stability of the composite. Fine size reinforcements of $\mathrm{ZrB}_{2}$ formed in the Al matrix due to phase nucleation, which facilitated the wetting and bonding of the interface between the reinforcements and the matrix. The melt boiling at the high temperature distributed the particles throughout the mold and ensured homogeneous distribution.

\subsection{Flank Wear}

Abrasion is the main wear mechanism in flank wear during machining. Flank wear is one of the major factors contributing to the geometric error and thermal damage in a machined work piece [21]. The presence of fine $\mathrm{TiB}_{2}$ particles in the composites causes less damage when engaging the cutting tool with the reinforcements. The $\mathrm{Al}_{2} \mathrm{Cu}$ formation surrounded by the reinforcements reduces the abrasive action at the flank face of the tool. Figure 6 shows the effects of cutting speed on flank wear when machining the composites at $0.2 \mathrm{~mm} / \mathrm{rev}$ feed rate and $1 \mathrm{~mm}$ depth of cut. Figure 6 reveals that the increase in cutting speed, increases the flank wear under the same machining conditions. At higher cutting speeds, the material passes away within a short interval of time, which facilitates the machining interface to become the adiabatic system. Increase in temperature softens the cutting tool and causes more tool wear. The effect of feed rate on flank wear was recorded by keeping the cutting speed as $125 \mathrm{~m} / \mathrm{min}$ and depth of cut as $1 \mathrm{~mm}$. Figure 7 shows that higher feed rate increases the flank wear. A rise in the federate increases the friction between work piece and hikes up heat generation which causes greater flank wear. It is observed from Figure 7 that the flank wear increases through an increase in the reinforcement ratio. The presence of small and fine reinforcement particles reduces the tool wear because of the absence of coarseness. $\mathrm{Al}_{2} \mathrm{Cu}$ phase surrounded by the $\mathrm{TiB}_{2}$ particles acts as a lubricant and reduces the effect of reinforcements.

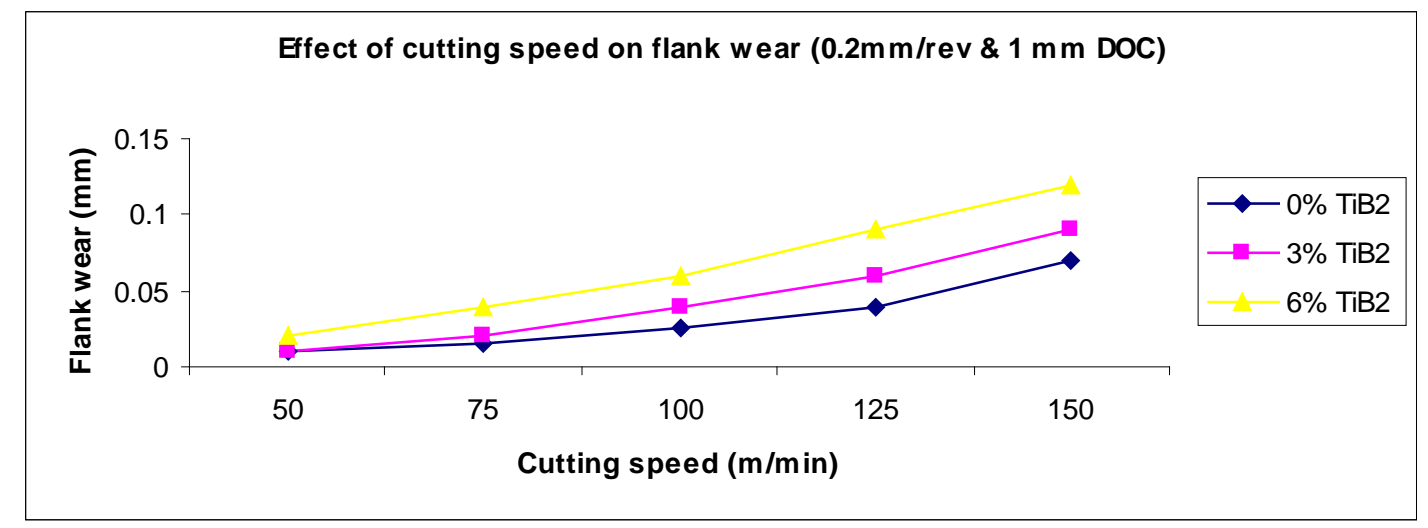

Figure 6 Effect of cutting speed on flank wear

\subsection{Cutting Force}

Cutting force signals are highly sensitive carriers of information about the status of the machining process. The influence of cutting speed on cutting force is shown in Figure 8. This shows that an increase in cutting speed decreases the cutting force. An increase in cutting speed increases the temperature of the work piece, which reduces the hardness of the work piece. Therefore, the cutting force is reduced when this softened work piece is machined. The effect of 
the feed rate on the cutting force was measured by keeping the cutting speed constant at 125 $\mathrm{m} / \mathrm{min}$ and the cut at $1 \mathrm{~mm}$ depth. As seen from Figure 9, an increase in feed rate increases the cutting force. Generally, the cutting force along the horizontal axis increases when the feed rate is increased. An increase in feed rate increases the maximum chip thickness, which increases the cutting force. As seen from Figures 8 and 9, as the reinforcement ratio increases the cutting force is reduced due to a reduction in strain.

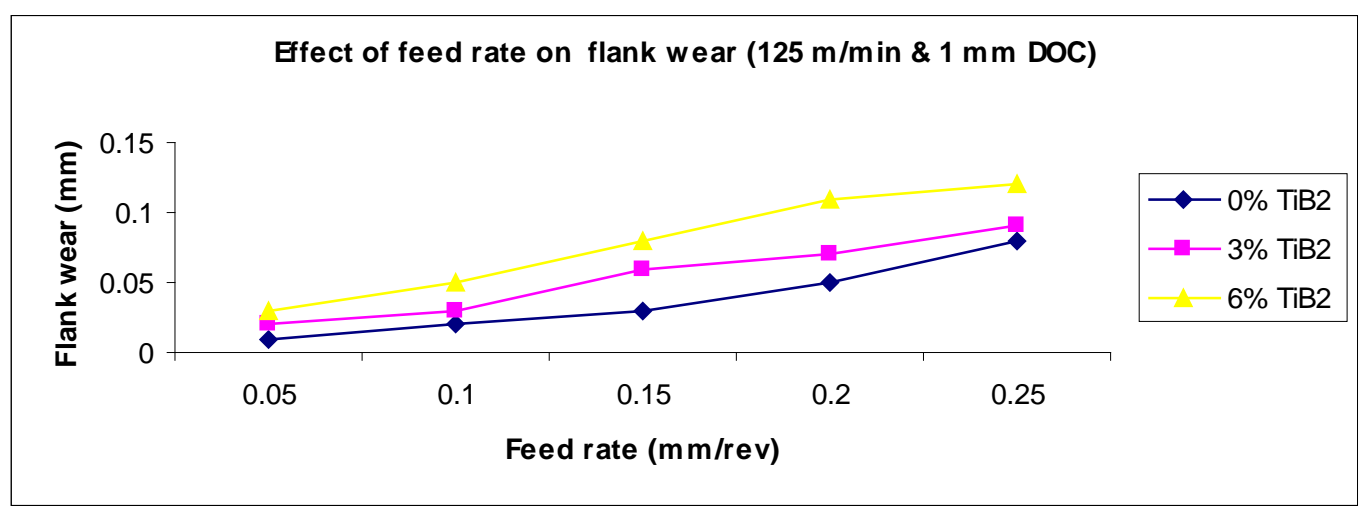

Figure 7 Effect of feed rate on flank wear

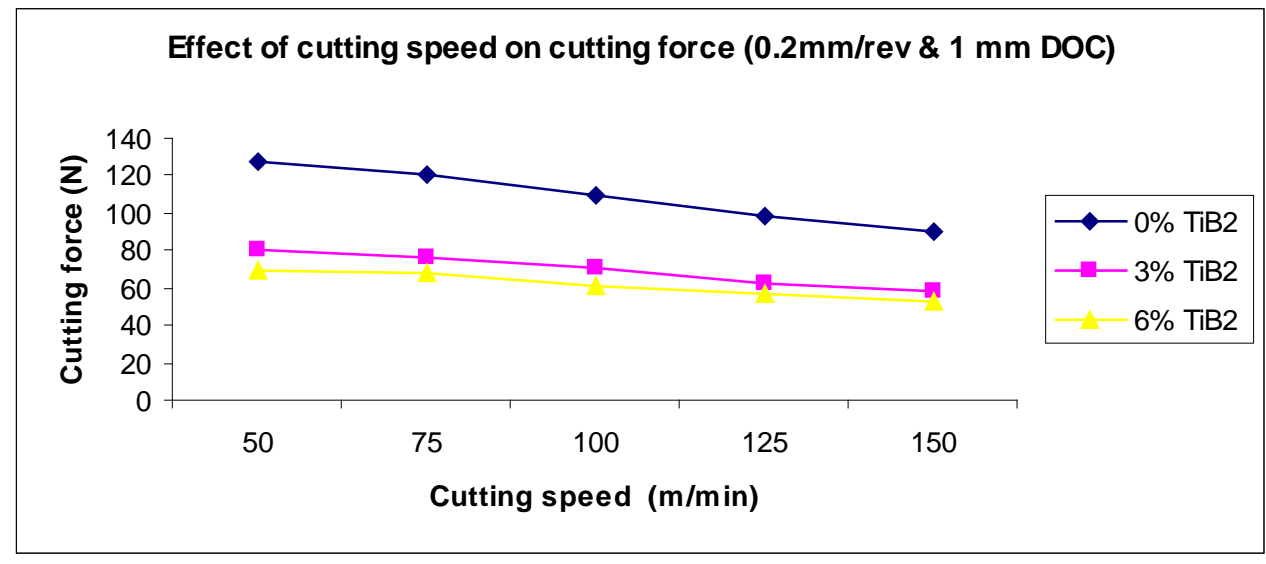

Figure 8 Effect of cutting speed on cutting force 


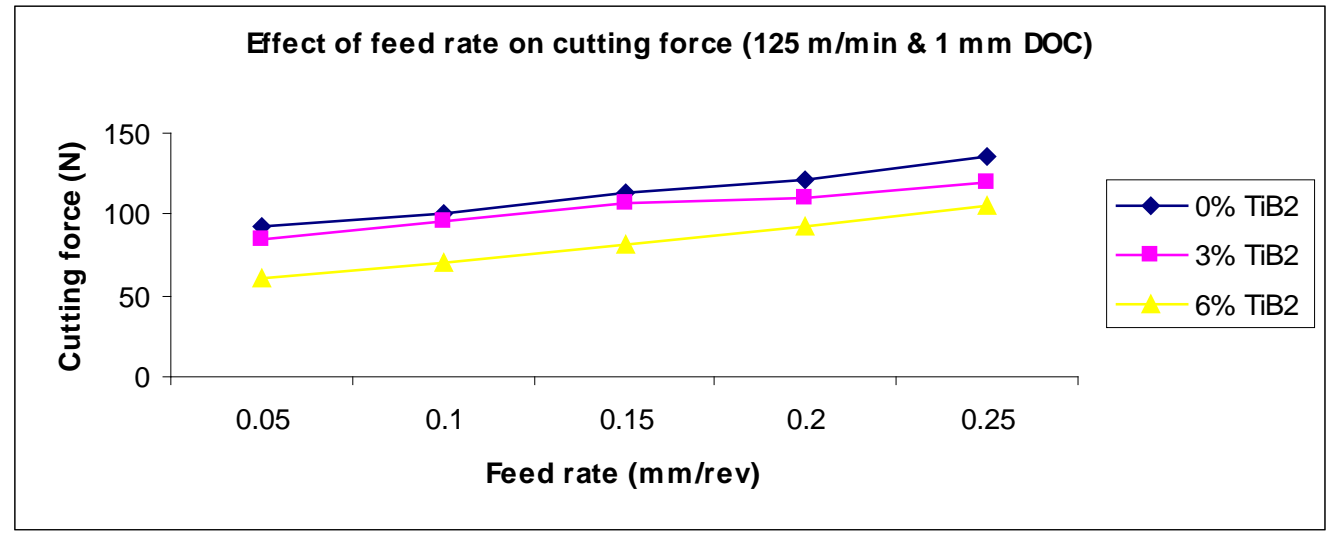

Figure 9 Effect of feed rate on cutting force

\subsection{Surface Roughness}

The machined surface quality of the composite is one of the most important factors affecting the actual application. Figure 8 shows the influence of cutting speed on surface roughness. The surface roughness was evaluated under different cutting speeds, at a constant feed rate of $(0.2$ $\mathrm{mm} / \mathrm{rev}$ ) and a depth of cut $(1 \mathrm{~mm})$. As seen from Figure 8, an increase in cutting speed reduces the surface roughness. Higher cutting speeds are associated with an increase in the cutting temperature which leads to the formation of suited-up edge formations and minimizing the deposition of build-up edge formation. A higher cutting speed can however, improve the surface finish. As the cutting speed increases, the strain rate will also increase. This action facilitates particle fracture and crack-minimizes particle pulling. Therefore, the amount of pin formation is reduced and good surface finish can be achieved. The effect of feed rate on the surface roughness examined by keeping the cutting speed at $125 \mathrm{~mm} / \mathrm{m}$ and depth of cut as $1 \mathrm{~mm}$ is observed from Figure 9. An increase in feed rate increases the surface roughness. An increase in feed rate increases the pit and crack formation, and causes larger tool feed marks. At higher feed rates, the tool has more vibration when shifting the cutting from Particle to matrix. This could be the reason for larger feed marks at higher feed rates. The increase in feed rate increases the temperature, which enables particle pulling, and pits and crack formation. These effects increase the surface roughness at higher feed rates. These small sized $\mathrm{TiB}_{2}$ particles and improved wettability minimize the possibility of particle pulling, de-bonding of the matrix - reinforcement. The uniform distribution of the particles undergoes uniform plastic deformation which reduces subsurface damage. These effects minimize surface roughness in machining the composites. Figures 8 and 9 show that the surface roughness has been increased by increasing the volume fraction of the composite. 


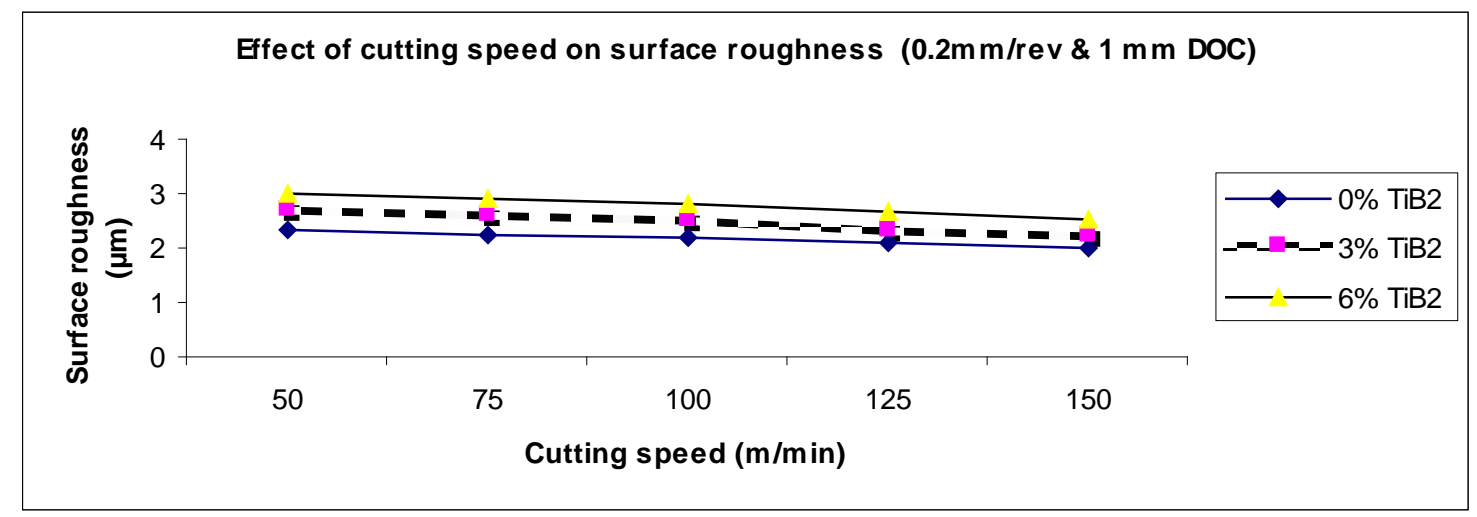

Figure 10 Effect of cutting speed on surface roughness

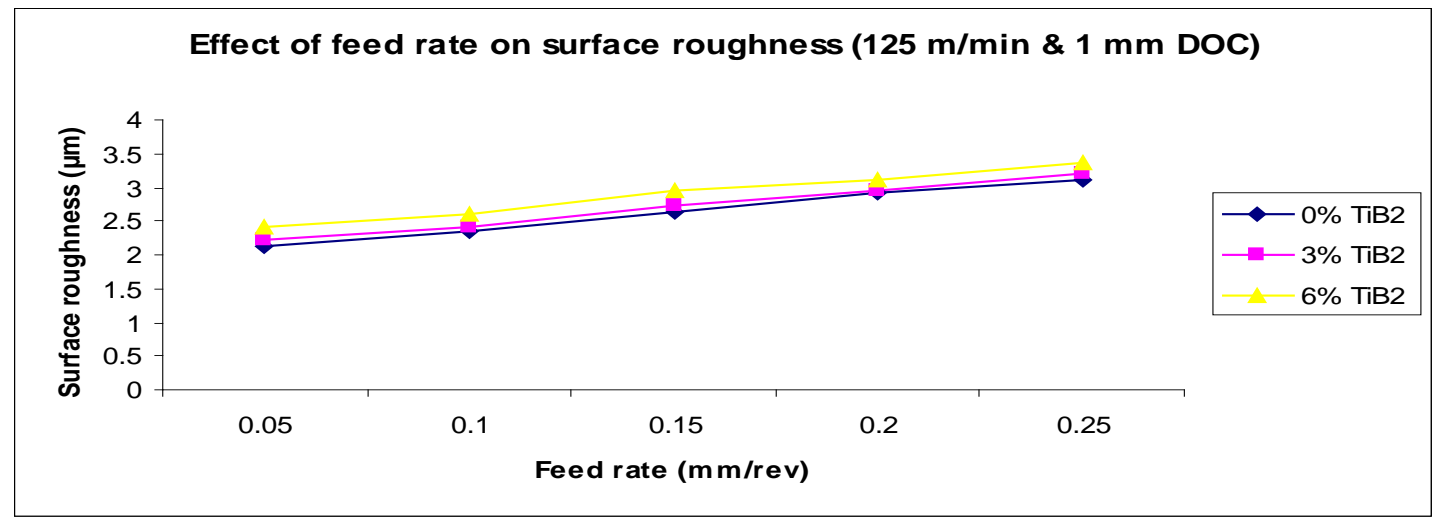

Figure 11 Effect of feed rate on surface roughness

\section{CONCLUSION}

The flank wear, cutting force, and surface roughness of the experimental study of machining the $\mathrm{Al}-5 \mathrm{Cu}-\mathrm{TiB}_{2}$ in-situ metal matrix composites indicated the following conclusions:

Al-5Cu- $\mathrm{TiB}_{2}$ in-situ metal matrix composite has been synthesized successfully with different reinforcement ratio using flux-assisted synthesis.

The presence of $\mathrm{TiB}_{2}$ and $\mathrm{ZrB}_{2}$ phases in the $\mathrm{Al}-5 \mathrm{Cu}$ alloy is confirmed by EDAX analysis.

A significant improvement in the hardness was observed by adding reinforcements in the $\mathrm{Al}-5 \mathrm{Cu}$ alloy.

The increase in cutting speed increased the flank wear, reduced the cutting force, and minimized the surface roughness.

An increase in feed rate increased the flank wear, cutting force, and surface roughness. 
An increase in reinforcement ratio increased the tool wear, reduced the cutting force, and increased the surface roughness.

The machinability behavior of $\mathrm{Al}-5 \mathrm{Cu}-\mathrm{TiB}_{2}$ is entirely different from the conventional composites because of the presence of $\mathrm{Al}_{2} \mathrm{Cu}$ phase, $\mathrm{TiB}_{2}$, and $\mathrm{ZrB}_{2}$ particles.

This detailed of study of machining characteristics would be helpful for the economic and efficient machining of this material.

\section{ACKNOWLEDGEMENTS}

The Author acknowledges the encouragement and support provided by the management of Swetha Institute of Technology and Science for Women, Tirupati. Author also grateful to the AICTE, India for the provision of grant (8024/RID/BOR/MOD/831/9/10) to carry out this experimental work.

\section{REFERENCES}

[1] Kuruvilla A.K., Prasad K.S., Bhanuprasad V.V., Mahajan Y.R., "Microstructure-property correlation in Al-TiB2 (XD) composites” Scripta Metall., vol. 24, 1990,pp. 873-878.

[2] Cui C., Shen Y., Meng, F., "Review on fabrication methods of in-situ metal matrix composites” J. Mater. Sci. Tech., vol.16, 2000, pp.619-626.

[3] Ramesh C.S., Ahamed A., Channabasappa B.H.,Keshavamurthy R., “Development of Al 6063-TiB2 in situ composites” Mater.Des., vol.31, 2010, pp. 22302236.

[4] Feng C.F., Froyen L., "Microstructures of in-situ Al/TiB2 MMCs prepared by a casting route” J. Mater. Sci., vol.35, 2000, pp.837-850.

[5] Lewis D., "In-situ reinforcement of metal matrix composites: processing and interface" Academic Press, London, 1991, pp 121-150.

[6] Janghorban K., "Processing of ceramic matrix SiC-Al composite” J. Mater. Proc. Techno., vol. 38, 1993, pp. 361-368.

[7] Lakshmi S., Lu L.,Gupta M., "In-situ preparation of TiB2 reinforced aluminum based composites” J. Mater. Proc. Techno., vol. 73, 1998, pp.160-166.

[8] Lee K.T., Lu L., Lai M.O., "Synthesis of in-situ Al-TiB2 composite using stir cast route" Compo. Struct., vol. 47, 1999, pp. 589-593.

[9] Emamy M., Mahta, M., Rasizadeh, J., "Formation of TiB2 particles during dissolution of TiAl3 in Al-TiB2 metal matrix composite using an in-situ technique” Compo. Sci. Techno., vol.66, 2006, pp.1063-1066.

[10] Fan T., Yang G., Zhang D., “Thermodynamic effect of alloying addition on in-situ reinforced TiB2/Al composites” Metallur.Mater. Trans.A, vol.36, pp225-233.

[11] Lu L., Lai M.O., Chen F.L., "Al-4 wt\% Cu composite reinforced with in-situ TiB2 particles” Acta Materialia, Vol.10, 1997, pp. 4297-4309.

[12] Liang Y., Zhou J., Dong S., Yang T ., "Thermodynamic analysis of the formation of In-situ reinforced phases in cast Al-4.5Cu alloy” J. Wuhan University of Techno. Mater. Sci. Ed, vol. 23, 2008,pp.342-345. 
[13] Herbert M.A., Sarkar C., Mitra R., Chakraborty M., "Microstructural evolution, hardness, and alligatoring in the mushy state rolled cast $\mathrm{Al}-4.5 \mathrm{Cu}$ alloy and in-situ $\mathrm{Al} 4.5 \mathrm{Cu}-5 \mathrm{TiB}_{2}$ composite” Metall. Mater. Trans. A, vol. 38, 2007, pp. 2110-2126.

14] Kumar S., Subramanyasarma V., Murty B.S., "High temperature wear behavior of Al-4CuTiB2 in-situ composites” Wear, vol. 268, 2010, pp. 1266-1274.

[15] Dabade U.A., Joshi S.S., "Analysis of chip formation mechanism in machining of Al/SiCp metal matrix composites” J.Mater. Proc. Techno., vol. 209,2009,pp. 4704-4710.

[16] Quan Y.M.., Zhou Z.H.,Ye B.Y., "Cutting process and chip appearance of aluminum matrix composites reinforced by SiC particle” J. Mater. Process. Technol.,vol.91,1997, pp.231-235.

[17] Ozcatalbas Y., "Chip and built-up edge formation in the machining of in situ $\mathrm{Al}_{4} \mathrm{C}_{3}-\mathrm{Al}$ composite”. Mater. Des., vol.24, 2003a, pp.215-221.

[18]OzcatalbasY., "Investigation of the machinability behavior of $\mathrm{Al}_{4} \mathrm{C}_{3}$ reinforced Al-based composite produced by mechanical alloying technique” Compo. Sci. Technol., vol.63,2003, pp.53-61.

[19] Rai R.N., Datta G.L., Chakraborty M., Chattopadhyay A.B., "A study on the machinability behavior of Al-TiC composite prepared by in-situ technique” Mater. Sci. Eng.: A, vol. 428, 2006, pp.34-40.

[20] Anandakrishnan V., Mahamani A., “Investigations of flank wear, cutting force, and surface roughness in the machining of Al-6061-TiB2 in situ metal matrix composites produced by flux-assisted synthesis” Int J Adv Manuf Technol., vol. 55, 2010,pp.65-73.

[21] Yanming Q., Zehua Z, “Tool wear and its mechanism for cutting SiC particle-reinforced aluminium matrix composites” J. Mater. Proc. Techno., vol. 100, 2000, pp.194-199. 